\title{
O CAMPO SEMÂNTICO “JOGOS E DIVERSÕES INFANTIS” NA REGIÃO NORTE DO BRASIL: UMA DESCRIÇÃO GEOSSOCIOLINGUÍSTICA
}

\author{
THE SEMANTIC FIELD “CHILDREN'S GAMES AND FUN” IN THE NORTH \\ REGION OF BRAZIL: A GEOSOCIOLINGUISTIC DESCRIPTION
}

Josevaldo Alves Ferreira ${ }^{1}$

http://lattes.cnpq.br/2665285808113083

Enviado em: 31/07/2020

Aceito em: 22/09/2020

\begin{abstract}
RESUMO: este trabalho pretende mapear a produção lexical do campo semântico "Jogos e Brincadeiras Infantis" em seis estados da região norte do Brasil - Pará, Amapá, Amazonas, Rondônia, Acre e Tocantins - os quais fazem parte da rede de pontos do projeto Atlas Linguístico do Brasil (ALiB) e, desse modo, fazer uma análise comparativa entre os dados urbanos (capitais) e rurais (interior), assim como observar subáreas geográficas onde ocorram itens lexicais comuns. A metodologia seguida observará os preceitos advindos da dialetologia pluridimensional utilizada por Thun (1998), assim como as contribuições feitas por pesquisadores da área como Cardoso (2010) e Razky (2013). Os resultados serão apresentados por meio de cartas linguísticas, que demonstrem a variação lexical dos itens pesquisados do ponto de vista diatópico, e de gráficos que apresentem a variação diastrática (idade e sexo). Os dados analisados na pesquisa fazem parte do acervo do projeto ALiB e foram coletados em 23 localidades dos estados acima mencionados considerando falantes de ambos os sexos, de duas faixas etárias de idade (18 a 30 e 50 a 65 anos de idade), com nível fundamental incompleto de educação. Os resultados evidenciam que o campo semântico analisado não apresenta grandes diferenças lexicais entre as capitais e as cidades do interior mas apontam para a existência de duas subáreas que apresentam características lexicais comuns a essas subáreas. Outrossim, a variação diagenérica mostra pouca variação entre homens e mulheres no campo semântico observado. Quanto à idade, verifica-se certo conservadorismo nos falantes mais velhos, os quais preferem os usos lexicais mais peculiares na região norte.
\end{abstract}

Palavras-chave: Dialetologia Pluridimensional. Geossociolinguistica. Variação Lexical.

\begin{abstract}
This projects aims to map the lexical production of the semantic field "Infant Games and Plays" in six states of the north region of Brazil which are: Pará, Amapá, Acre, Rondônia, Amazonas and Tocantins, which belong to the Linguistic Atlas of Brazil Project network (ALIB) so that a comparative analysis could be made between rural and urban area data as well as observe geographical subareas where commom lexical itens might occur. The Project follows the methodology used by Thun (1998) in addition to the contributions made by such authors like Cardoso (2010) and Razky (2013). The results will be presented through linguistic maps showing the lexical variation of the semantic field researched following the diatopic point of view and graphics showing the diastratic variation (age and gender). The analyzed data belong to the ALIB Project that have been collected in 23 counties of the states mentioned above considering speakers of both genders with two diferente age gaps (18 to 30 years old and 50 to 65 years old), who had not finished the elementary course at school. The results show that there are not considerable lexical diferences between the capital cities and small towns but indicate the existence of two subareas that have commom lexical items. Moreover, the diageneric variation show little diferences. On the other hand, older speakers seem to be more conservative than the young ones, prefering lexical items which are more peculiar to the north region of Brazil.
\end{abstract}

Keywords: Pluridimensional Dialectology, Geosociolinguistic, Lexical Variation.

1 Mestre em Linguística pela Universidade Federal do Pará, professor do Instituto Federal do Pará. e-mail: josevaldo.ferreira@ifpa.edu.com 


\section{Introdução}

Conhecer a realidade linguística do Brasil, no que tange a língua portuguesa, tem sido alvo de pesquisa em todo o território nacional. Esses estudos têm mostrado as nuances das variedades linguísticas do português brasileiro em diversos níveis como o fonético, morfossintático, lexical, etc. A região norte do país também tem tido seu acervo lexical estudado por interessados no assunto. Assim, artigos, dissertações e teses têm sido produzidos na linha de estudo do léxico, dentro os quais podemos citar a "Variação lexical nos dados do projeto Atlas Geossociolinguístico do Amapá" (SANCHES, 2015), "Um olhar lexical sobre a identidade dos migrantes interioranos do estado do Amazonas: um estudo sociogeolinguístico (GONÇALVES, 2015)", "Variação semântico lexical no Amapá" (SANCHES \& SILVA, 2014), "Um recorte da variação lexical no projeto Atlas Linguístico do Pará ( RAZKY \& GUEDES, 2013), Atlas dos falares do baixo Amazonas - AFBAM (BRITO, 2011), Glossário ilustrado dos nomes de doenças, pragas e plantas daninhas da cultura agrícola do estado do Acre (DANTAS, 2013), Variação Lexical no Nordeste Paraense (COSTA, 2005), Aspectos dialectológicos e lexicográficos do atlas etnolingüístico do Acre. (SOUZA, 2005.), entre outros.

Este trabalho pretende contribuir com os estudos do léxico da região norte do Brasil analisando e comparando os seus falares no que concerne à variação semântico-lexical relativo ao campo semântico "Jogos e Diversões Infantis", a partir das informações do banco de dados do projeto Atlas Linguístico do Brasil (ALiB). Para o desenvolvimento da pesquisa, segui-se os preceitos teóricos da Dialetologia Pluridimensional (Thun, 1998) e as observações de Razky (2013) e Cardoso (2010). De acordo com essa abordagem teórica, os dados analisados devem refletir aspectos relacionados às características sociais dos falantes, como, entre outros, idade e sexo, além de aspectos areais, verificando as variações dentro do espaço social (vertical) e geográfico (horizontal), para se obter um panorama dos falares de uma dada área o mais próximo possível de sua realidade.

O trabalho está dividido em quatro partes. A primeira apresenta o aspecto teórico utilizado na produção da pesquisa. A segunda aborda a metodologia empregada para o tratamento dos dados e sua posterior apresentação em forma de cartas linguísticas e gráficos. A terceira parte expõe os resultados alcançados após a análise dos dados de quatro cartas linguísticas e a última parte traz as considerações finais acerca do trabalho.

\section{Aspectos Teóricos}

Em sua trajetória, os estudos linguísticos de cunho dialetológico foram alvo de críticas de alguns linguistas (Trudgill,1999) a respeito da maneira como os dados desses estudos eram trazidos a público, pois, eram apresentados dando conta das diferenças entre dialetos diversos, sob o ponto de vista geográfico, funcionando somente como um registro dos falares. Ao levar em conta apenas aspectos geográficos em suas pesquisas, a Dialetologia era considerada apenas como uma mera apresentadora de dados. Para Trugdgill (1999) “... dialectologists are engaged in collecting data for the sake of collecting data"2. Assim, as informações advindas das pesquisas dialetológicas acabavam sendo utilizadas por pesquisadores de outros ramos linguísticos. William Labov, por exemplo, teria feito uso dos dados das pesquisas advindas do Atlas Linguístico dos Estados Unidos e Canadá, os quais forma coletados de um ponto de vista dialetológico.

A partir da década de 60 do século XX, com a expansão dos estudos sociolinguísticos, principalmente os de orientação Laboviana, as pesquisas linguísticas possibilitaram a anexação de fatores externos ao sistema linguístico em suas análises. Classe social, idade, sexo, profissão, entre outros aspectos relativos ao usuário da língua, que eram ignorados na perspectiva estruturalista, ganham importância no estudo das variedades linguísticas de uma determinada comunidade. No Brasil, por exemplo, os primeiros projetos de produção de Atlas Linguísticos regionais eram predomi-

2 “Dialetólogos estão envolvidos em coletar dados apenas por coletar” (Trudgill, 1999,p.02). Tradução nossa. 
nantemente monodimensionais e tratavam acima de tudo da dimensão geográfica, como o pioneiro Atlas Prévio dos Falares Baianos (1963), mas, com o avanço das pesquisas, as investigações passaram a incluir em suas análises as características sociais dos falantes com o intuito de retratar com mais nitidez a realidade linguística de determinada região.

Essa mudança de perspectiva em relação ao tratamento das informações linguísticas de determinada área se deu com a cooperação do construto teórico de duas disciplinas independentes, Sociolinguística e Dialetologia, pois ambas tinham pelo menos um ponto em comum, ou seja, preocupavam-se com a questão da variação linguística. A primeira com a variação social e a segunda com a variação areal. A essa união de aspectos teóricos dessas disciplinas, convencionou-se chamar de Dialetologia Pluridimensional e Relacional (THUN, 1998). Para este autor:

La dialectologia areal y la sociolingüística disciplinas históricamente separadas, confluyen em una geolingüística ampliada que puede llamar-se oportunamente "Dialectologia Pluridimensional" y que se entiende como parte de la ciencia general de la variacion lingüística y de las relaciones entre variantes y variedades por un lado y ablantes por el outro. (THUN, 1998, p. 704)

A dialetologia pluridimensional, como já dito, retrata os falares considerando as perspectivas geográfica e social com a finalidade de coletar, tratar, analisar e descrever os fatos linguísticos de determinada área com precisão mais próxima possível da realidade linguística analisada. Razky (2013) declara que:

os atlas linguístico multidimensionais, inspirados, portanto, nos avançados estudos sociolinguísticos, mapeiam outras variantes além da diatópica (geográfica), como: diagenérica ou diassexual, diageracional, diastrática e diafásica, somente para citar as mais comuns.

No entanto, deve ser ressaltado que apesar de inscrever em suas pesquisas fenômenos sociais dos falantes de uma variedade linguística qualquer, os trabalhos dialetológicos têm por finalidade a observação dos fatos de um ponto de vista primordialmente diatópico. Essa é a sua atividade fim. A esse respeito afirma Elizaincin (2010, p. 17): "la dialectologia [...] es la disciplina más general que se ocupa de la variación, notoriamente la diatópica em Coseriu, no diatópica pero si diastrática y diafásica, fundamentalmente, em Labov". Dessa maneira, os resultados das variações dialetais são apresentados por meio de cartogramas que ilustram as diferenças entre os falares de uma área geográfica, possibilitando o traçado de linhas imaginárias (isolexias), agrupando tais falares de acordo com suas características próprias.

No Brasil vários trabalhos têm sido produzidos numa perspectiva pluridimensional. A título de exemplo temos o Atlas Linguístico de Pernambuco - ALIPe (2013), Atlas Linguístico Topodinâmico do Oeste de São Paulo - 2014, Atlas Linguístico de Curiúva - Paraná (2015), só para citar alguns. Callou (2010) aponta que:

os atlas linguísticos modernos acrescentaram uma dimensão vertical - social - à geográfica horizontal e as pesquisas dialetológicas passaram a observar toda e qualquer variação de natureza sócio-cultural, ciente que mesmo no dialeto rural mais isolado há elementos de diferenciação

Partindo do pressuposto de que as línguas variam no espaço geográfico e também no espaço social serão analisados os dados do campo lexical Jogos e Diversões Infantis na região norte do Brasil.

\section{Metodologia}

Para a elaboração deste estudo, foram utilizados os dados e a metodologia do projeto Atlas 
Linguístico do Brasil (ALiB). As informações foram coletadas in loco em seis estados da região norte brasileira, quais foram, Pará, Amapá, Amazonas, Acre, Rondônia e Tocantins. No total, vinte e três cidades foram investigadas utilizando-se o "Questionário Semânticolexical" do referido projeto. Este trabalho, no entanto, restringiu-se ao campo semântico "Jogos e Brincadeiras Infantis". Em cada estado os dados foram coletados nas seguintes localidades:

Quadro 1: Pontos de inquérito da pesquisa

\begin{tabular}{|c|c|l|}
\hline Estado & Número de localidades & \multicolumn{1}{|c|}{ Localidades } \\
\hline Pará & 10 & $\begin{array}{l}\text { Belém, Soure, Bragança, Almeirim, Óbidos, Altamira, Itaituba, Marabá, } \\
\text { Jacareacanga, e Conceição do Araguaia. }\end{array}$ \\
\hline Amazonas & 05 & $\begin{array}{l}\text { Manaus, Humaitá, Tefé, Benjamim Constant e São Gabriel da Cacho- } \\
\text { eira. }\end{array}$ \\
\hline Amapá & 02 & Macapá e Oiapoque \\
\hline Acre & 02 & Rio Branco e Cruzeiro do Sul \\
\hline Rondônia & 02 & Porto Velho e Guajará Mirim \\
\hline & 02 & Natividade e Pedro Afonso \\
\hline
\end{tabular}

Os mapas a seguir mostram a localização dessas localidades na região norte:

Figura 2: Localização das cidades pesquisadas - não-capitais

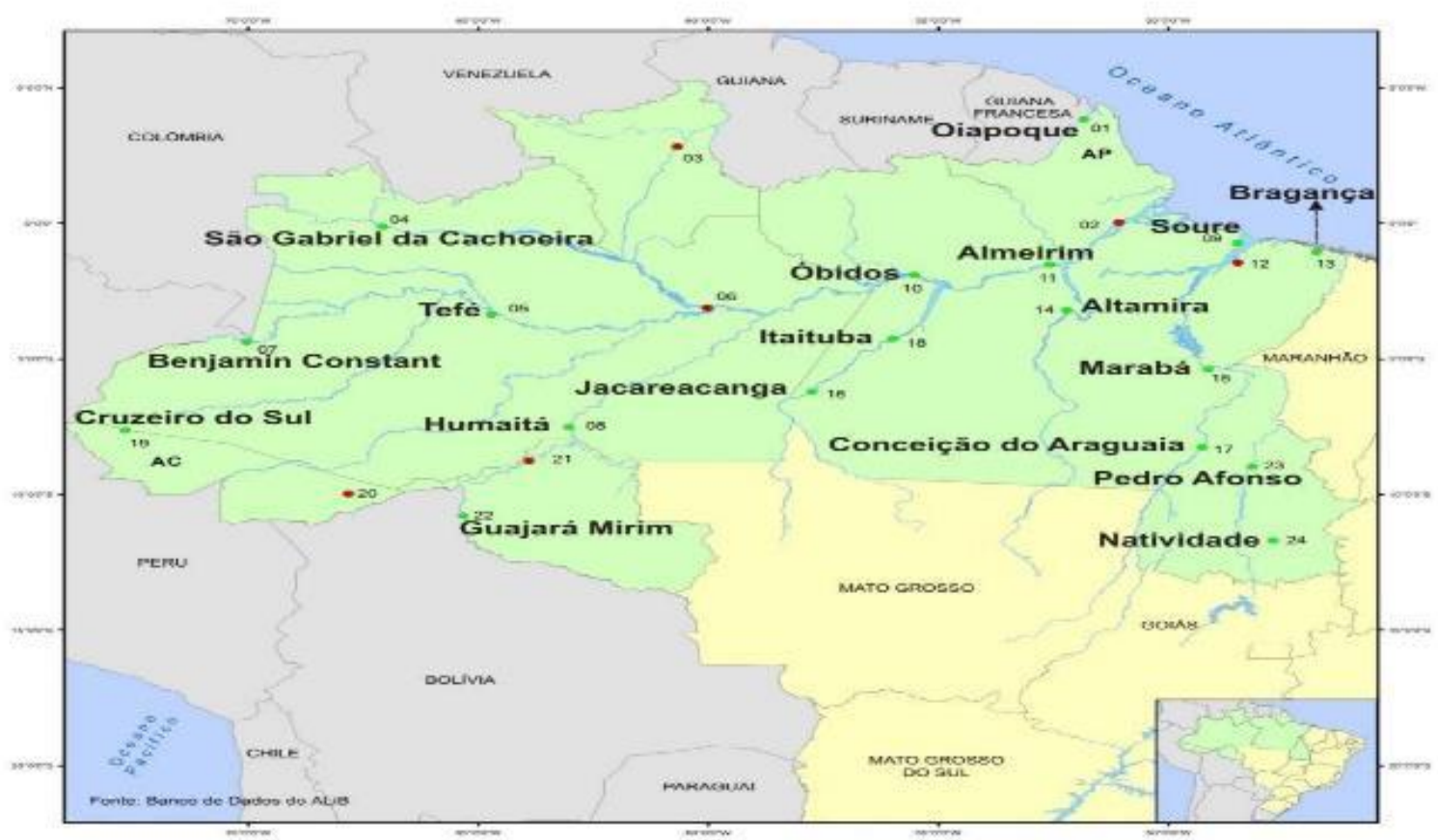


Figura 2: Localização das cidades pesquisadas - capitais

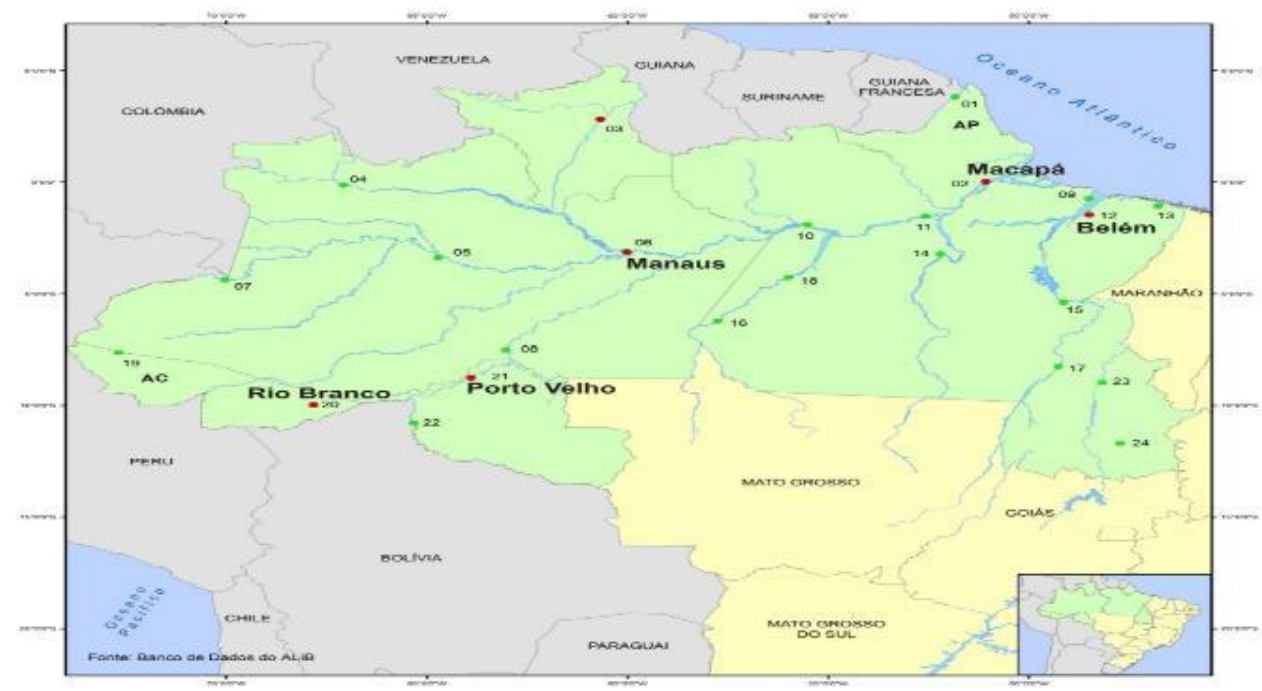

Foram entrevistados 92 falantes oriundos da própria região, com idade variando entre duas faixas etárias, 18 a 30 anos (primeira faixa etária) e 50 a 65 anos (segunda faixa etária), divididos equitativamente entre homens e mulheres, com grau de escolaridade que não excedesse o nível fundamental ${ }^{3}$. Os informantes devem ser naturais da localidade pesquisada e não terem residido em outra cidade por mais de um terço de sua vida e, caso tenham morado fora, que esse período não tenha coincidido com a fase de aquisição da língua. Seus pais devem também ser naturais da cidade pesquisada. Para a coleta de dados foi utilizado o questionário do projeto ALiB (COMITÊ, 2001), do qual esta pesquisa fez um recorte dos dados da área semântica "Jogos e Brincadeiras Infantis", questões 155 a 167, do questionário semântico-lexical. O campo semântico pesquisado foi recortado do arquivo de áudio do corpus do projeto ALiB com a utilização do programa de computador Cool Edit Pro 2.0. Em seguida, foram produzidas tabelas que demonstrassem quantitativa e qualitativamente os dados de cada umas das cidades, por meio do programa Excel 2010, para a posterior exposição dessas informações nas cartas lexicais. $O$ mapa utilizado para a elaboração das cartas pertence ao projeto ALiB e para a inserção das informações nas mesmas os programas computacionais Corel Draw e Photoshop foram de grande valia.

\section{Resultados Alcançados na Análise dos Dados}

Apresentamos os resultados alcançados na análise dos dados da região norte. A exposição desses resultados está organizada do seguinte modo: primeiramente será observado a dimensão diatópica sob o ponto de vista local, comparando-se os resultados das cidades do interior dos Estados com as suas respectivas capitais. A seguir, far-se-á uma análise demonstrando os agrupamentos lexicais na região norte (Razky, 2013). Finalmente, a dimensão social será apresentada por meio de gráficos, restringindo-se aos aspectos relativos ao gênero e idade dos informantes abordando os dois primeiros itens lexicais mais produtivos de cada pergunta do questionário e do campo semântico proposto.

Apresentamos a seguir a carta relativa ao primeiro item lexical analisado.

\footnotetext{
${ }^{3}$ A metodologia do projeto ALiB, na qual esse artigo se baseia, levou em conta, também, informantes com nível superior de educação nas capitais, porém, esta pesquisa analisará somente os dados de falantes com nível fundamental, mesmo nas capitais.
} 


\subsection{CARTA LEXICAL o1: CAMBALHOTA}

Figura 03: carta lexical do item cambalhota
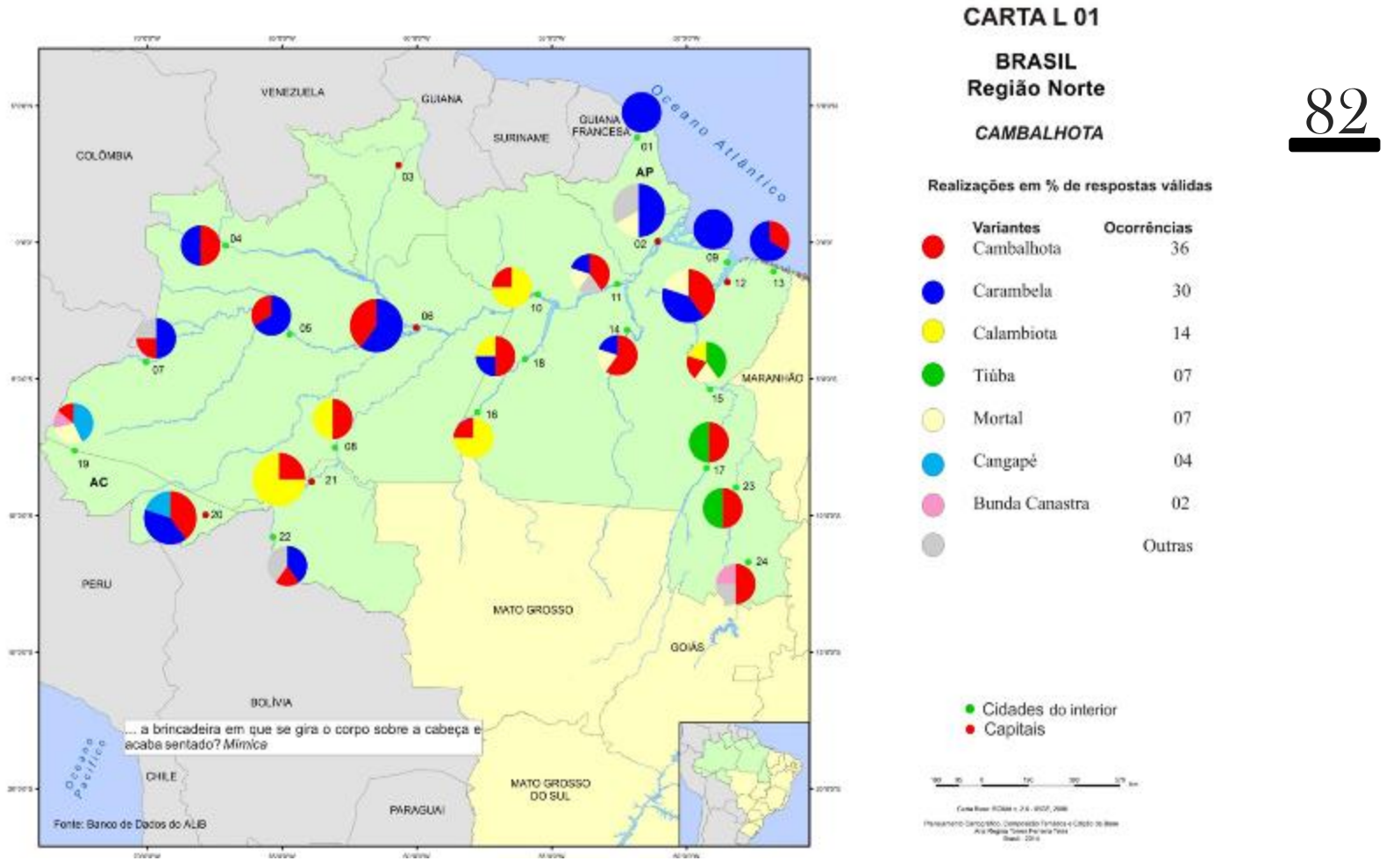

Do ponto de vista local, Belém (12), capital do estado do Pará, não apresenta diferenças marcantes em relação às cidades do interior. Nesta cidade cambalhota e carambela foram os itens lexicais mais produtivos. No interior do estado também. No entanto, os municípios de Óbidos (10), Itaituba (18), Jacareacanga (ponto 16) e Marabá (15), apresentaram a variante calambiota a qual não foi registrada na capital paraense. No Amazonas, Manaus (06) registrou carambela e cambalhota, o mesmo ocorrendo nas cidades interioranas. No Acre, a capital Rio Branco (20) e a cidade de Crmzeirn do Sul (19) tiveram em comum os itens cambalhota e cangapé, porém, a variante carambela to1 documentada somente na capital. Bunda canastra e mortal ocorreram apenas no interior do estado. Em Rondônia, calambiota e cambalhota foram comuns à capital e ao interior.

Observando as áreas com itens lexicais em comum, a carta demonstra que carambela ocorre com mais frequência no nordeste e noroeste da região norte brasileira e seu uso tende a diminuir à medida que se aproxima de regiões fronteiriças com outros estados como Mato Grosso, Goiás, Maranhão, por exemplo. No nordeste o item foi documentado em municípios do estado do Pará, nas cidades de Bragança (13), Soure (09), Belém (12), Almeirim (11), Altamira (14) e Itaituba(18), além dos municípios de Macapá (02) e Oiapoque (01), no estado do Amapá. No noroeste, foi registrado em Manaus (06), Tefé (05), Benjamin Constant (07) e São Gabriel da Cachoeira (04), todos no estado do Amazonas. Nota-se que carambela está presente nos dados de 03 estados diferentes, a saber, Pará, Amapá e Amazonas e, um pouco mais distante desses três estados, foi registrado também no Acre e Rondônia.

O item lexical calambiota está concentrado em uma área na faixa central da região que inclui as localidades de Óbidos (10), Itaituba (18) e Jacareacanga (16), no estado do Pará, Humaitá (08), no estado do Amazonas, e Porto Velho (21), em Rondônia. Outra área com item lexical comum diz respeito ao sudoeste da região norte, onde tiúba foi recorrente nas cidades de Marabá (15) e Conceição do Araguaia (17), no estado do Pará, assim como em Pedro Afonso (23) no estado do Tocantins.

Outro item registrado na região diz respeito a mortal o qual foi documentado em uma área 
que abrange as cidades de Macapá (02), Belém (12), Almeirim (11) e Altamira (14).

Com relação ao aspecto social, o gráfico a seguir demonstra o resultado da dimensão diagenérica para os dois itens lexicais mais recorrentes:

Gráfico 01: Frequência dos itens carambela e cambalhota - dimensão diagenérica.

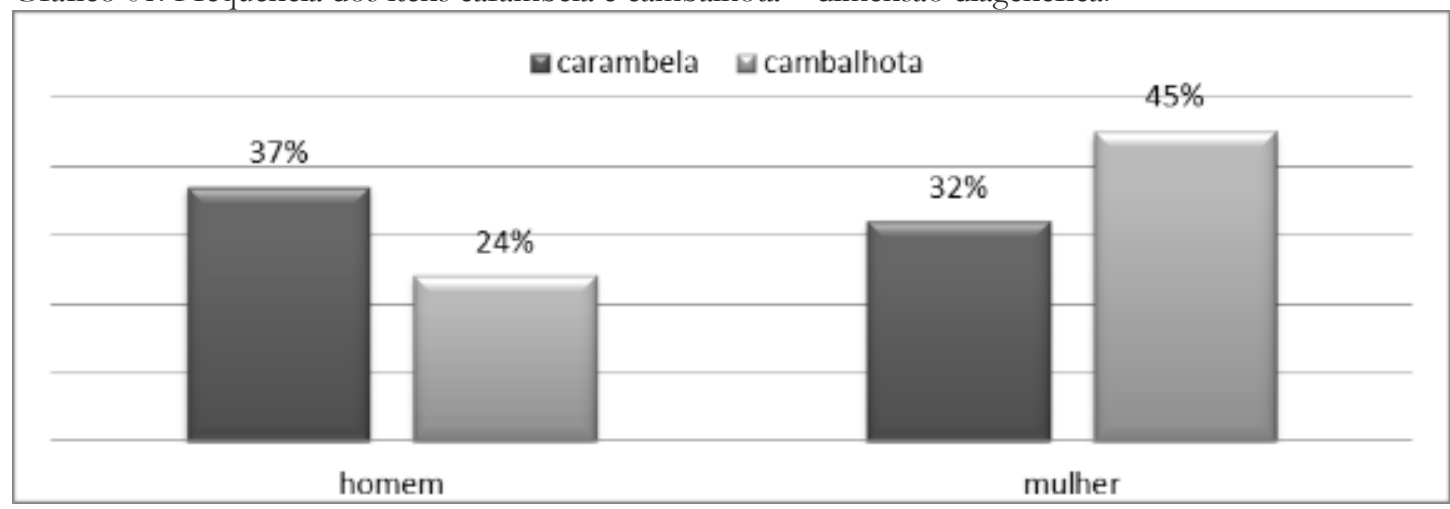

Observando a frequência de carambela verifica-se que os dois gêneros mostraram equilíbrio quanto ao seu uso, com os homens mencionando o item em 37\% das respostas e as mulheres em $32 \%$. Quanto à cambalhota, o sexo feminino mostrou preferência por essa lexia, com 45\% das respostas fornecidas, enquanto os homens o mencionaram em $24 \%$ das suas respostas. Desse modo, o resultado aponta para o uso um pouco mais frequente de carambela pelos homens e cambalhota pelas mulheres.

O próximo gráfico dá conta do aspecto diageracional:

Gráfico 02: Frequência dos itens carambela e cambalhota - dimensão diageracional.

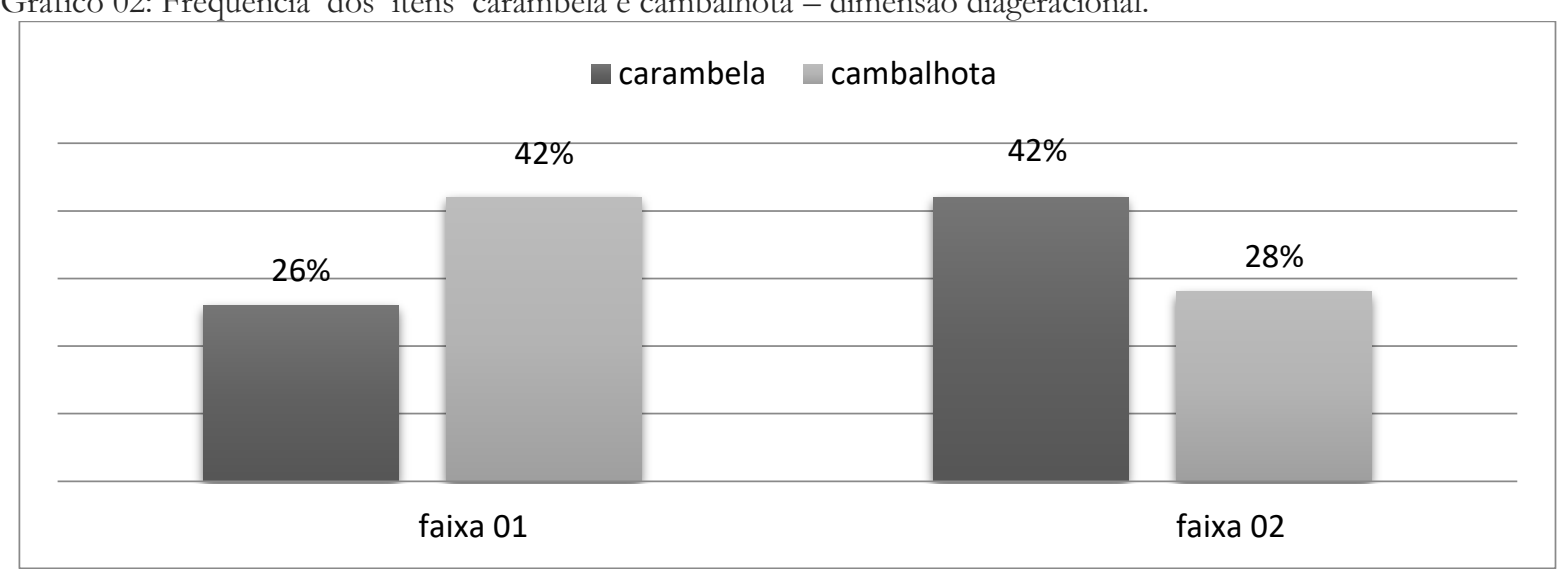

A dimensão diageracional demonstra preferências diferentes entre as duas faixas etárias analisadas. Os usuários mais jovens (faixa 01) mencionaram cambalhota em $42 \%$ de suas respostas, enquanto que os falantes mais velhos (faixa 02 ) preferiram carambela, com $42 \%$ do total das respostas fornecidas. Tal fato aponta para a possibilidade do item carambela cair em desuso no futuro, com a preferência por cambalhota pelas novas gerações de falantes.

\subsection{CARTA LEXICAL O2: BOLINHA DE GUDE}

Apresentamos a carta para análise das variações lexicais concernente ao item bolinha de gude, resultantes da questão 156 do questionário semântico lexical (QSL): 

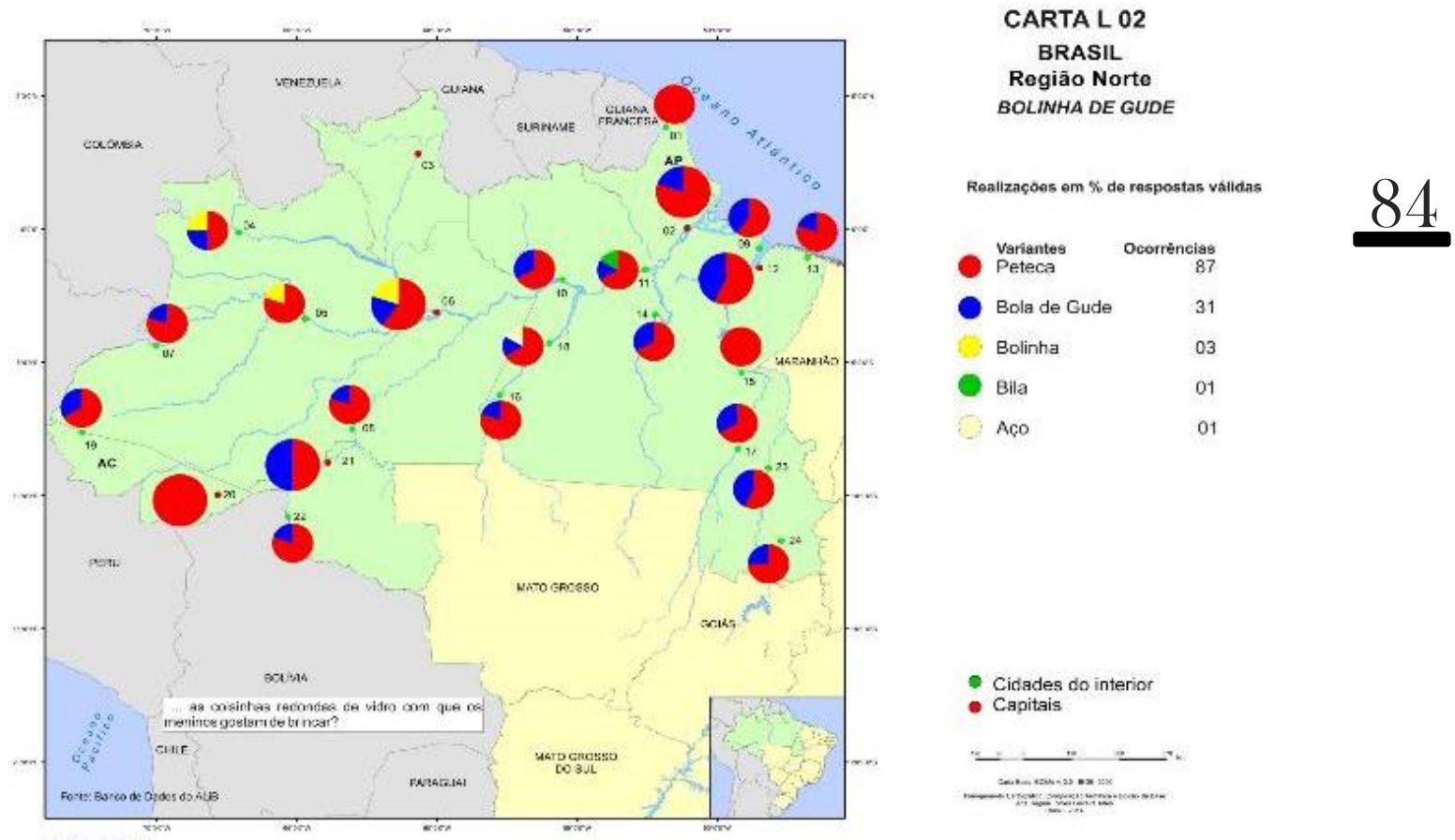

Do ponto de vista local os estados pesquisados não demonstraram diferenças substanciais entre as capitais e as cidades do interior. No Pará, a capital Belém (12) registra as mesmas formas lexicais que as cidades do interior, peteca e bola de gude. A variante bila foi mencionada em apenas uma localidade, Almeirim (11). No estado do Amazonas, Manaus (06) também registrou os mesmos itens lexicais encontrados no interior, quais foram peteca, bola de gude e bolinha, embora este último item não tenha sido registrado em todas as cidades interioranas. A capital do Acre, Rio Branco (20), registrou apenas peteca enquanto que a localidade de Cruzeiro do Sul (19), além desse item, mencionou bolinha de gude. Em Rondônia, Porto Velho (21) e Guajará Mirim (22) apresentaram as mesmas formas lexicais peteca e bola de gude. No Amapá, Macapá (02) também registrou peteca e bola de gude, mas este último item não foi registrado no Oiapoque (01).

Do ponto de vista regional, peteca e bola de gude estão distribuídos por toda a região norte, porém, peteca tem frequência bem mais significativa: $73 \%$ dos dados. Esse número sinaliza para a preferência do falante nortista ao uso de peteca à bola de gude. No entanto, a carta mostra uma subárea que inclui as localidades de Manaus (06), Tefé (05), e São Gabriel da Cachoeira (04), todas no Amazonas, onde a forma bolinha foi registrada.

Quanto ao aspecto social segue o gráfico que demonstra as preferências em relação ao gênero dos informantes: 
Gráfico 03: Frequência dos itens peteca e bola de gude - dimensão diagenérica.

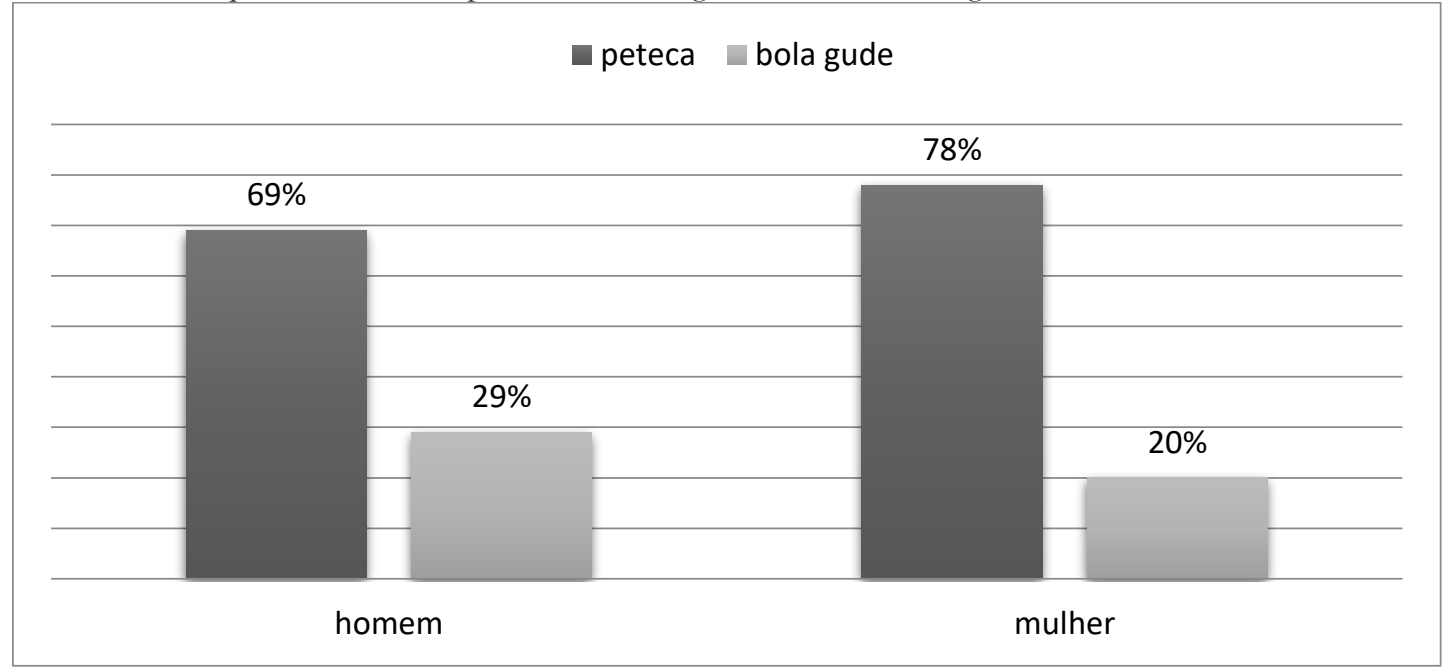

O gráfico confirma a preferência da região norte pelo item peteca nos dados analisados. Tanto os homens quanto as mulheres demonstraram alta frequência de uso do item lexical, com $69 \% \mathrm{e}$ $78 \%$ para cada gênero respectivamente. Observa-se que bola de gude não se mostrou tão popular entre os dois gêneros. Os homens citaram o termo em $29 \%$ de seus dados e as mulheres em $20 \%$ das suas respostas.

Com relação à idade dos informantes, o próximo gráfico apresenta os resultados:

Gráfico 04: Frequência dos itens peteca e bola de gude - dimensão diageracional.

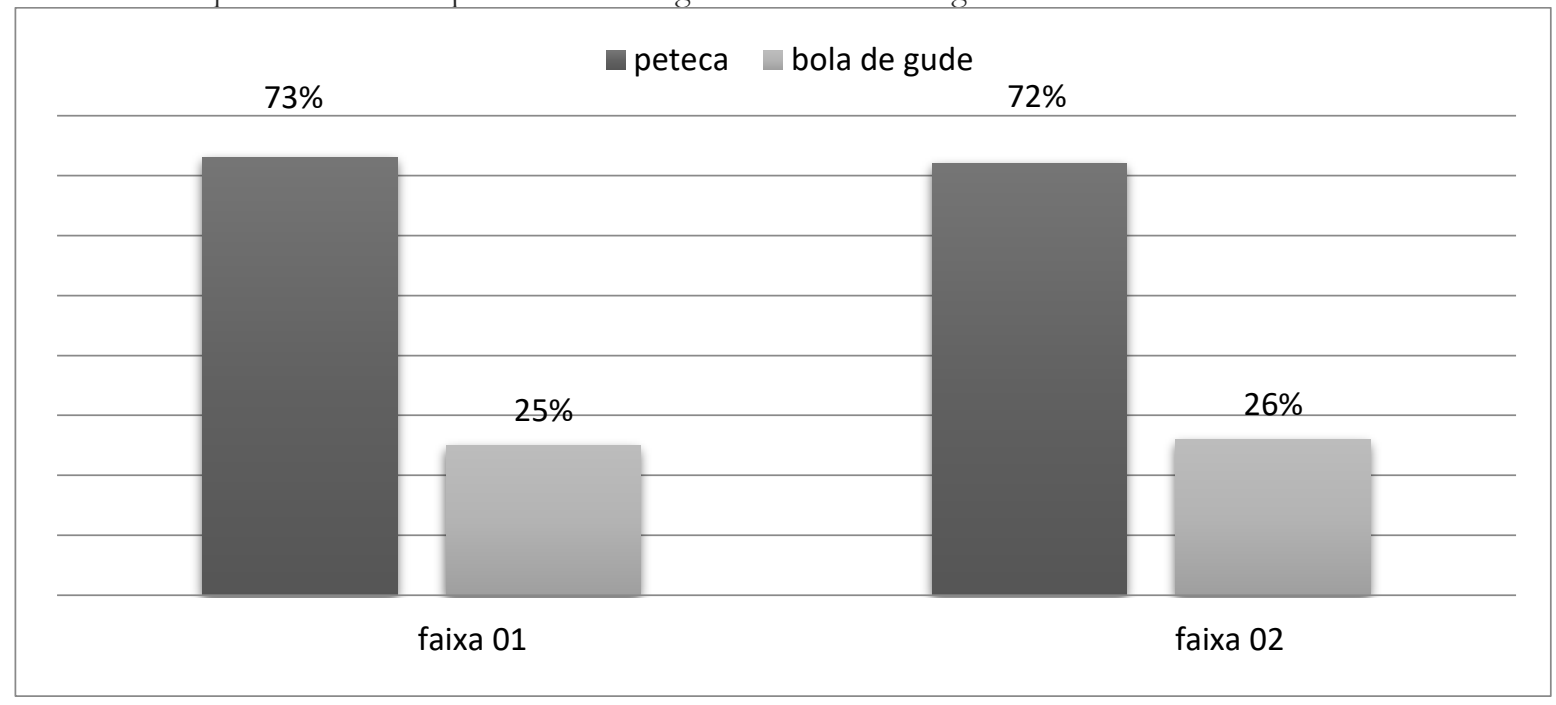

Com base no gráfico observa-se que a maioria dos informantes, tanto da primeira quanto da segunda faixa etária, demonstrou preferência por peteca com $72 \%$ e $73 \%$ respectivamente. A diferença entre o uso desse item e bola de gude é bastante significativa e confirma mais uma vez a preferência dos falantes da região norte pelo uso de peteca.

\subsection{CARTA LEXICAL O3: ESTILINGUE/SETRA/BODOQUE}

Para a análise dos itens lexicais estilingue, setra, bodoque, apresentamos a carta a seguir, na próxima página: 


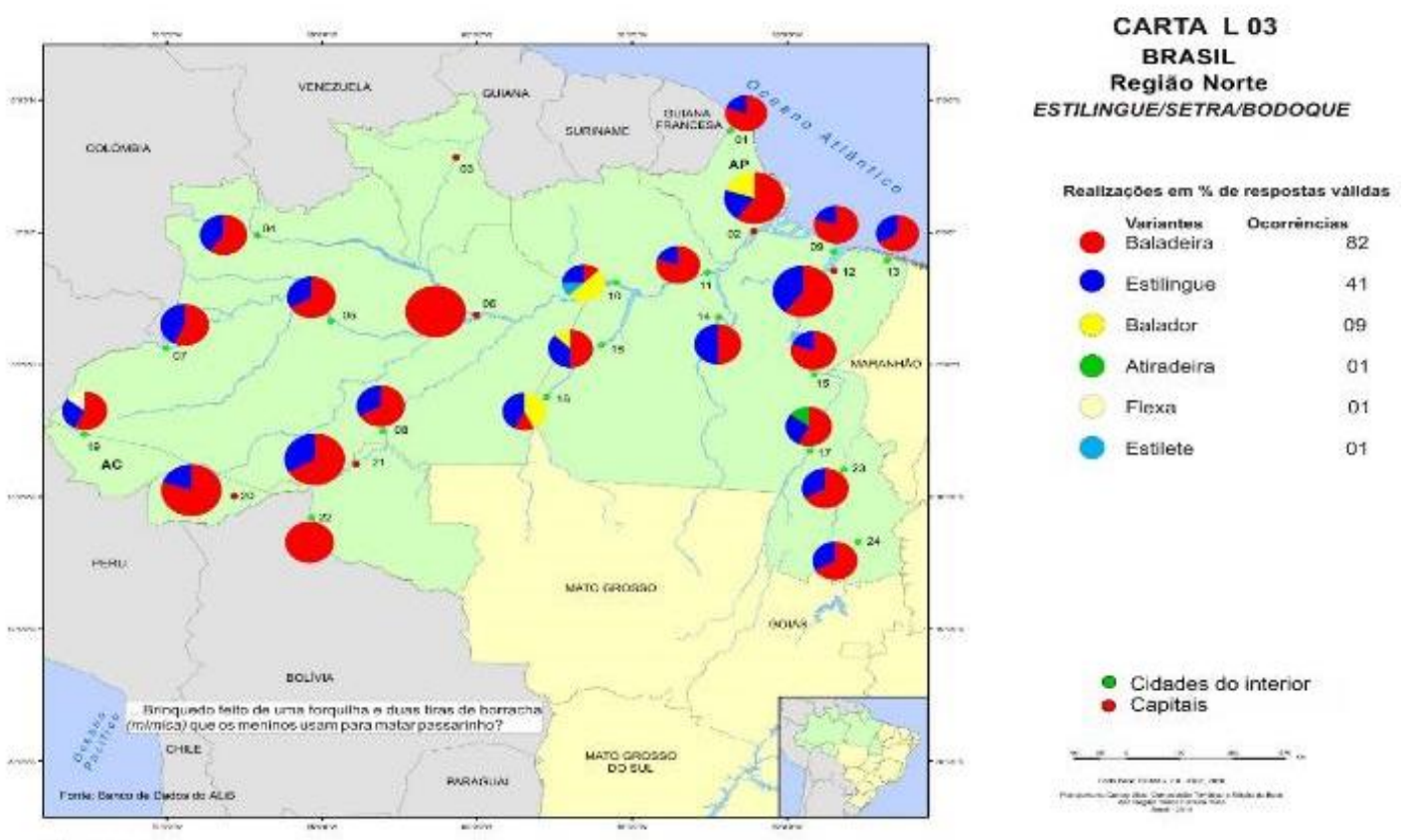

A análise da terceira carta mostra que tanto as capitais como as cidades do interior tendem ao uso de baladeira e estilingue. O Pará registrou os dois itens em todas as cidades pesquisadas. $\mathrm{O}$ entanto, as localidades de Óbidos (10), Itaituba (11) e Jacareacanga (16) tiveram em comum a forma balador à qual não ocorreu na capital, Belém. No Amazonas, baladeira foi o único item documentado na capital, Manaus (06). No interior do estado, além de baladeira, registrou-se, ainda, estilingue. Rio Branco (20), no Acre, documentou baladeira e estilingue, o mesmo ocorrendo no interior do estado onde também se registrou flecha. Guajará- Mirim (22), em Rondônia, não forneceu estilingue em suas respostas, que somente ocorreu em Porto Velho (21). No Amapá, foi documentado o item balador na capital, Macapá (02), o qual não foi registrado em Oiapoque (01). As duas localidades tiveram em comum os itens baladeira e estilingue.

Do ponto de vista regional, baladeira e estilingue foram os itens mais recorrentes. Baladeira, no entanto, parece ser o item mais representativo da região, com $61 \%$ das respostas registradas e encontra-se bem distribuído por toda a região norte.

A carta apresenta apenas uma subárea com forma lexical em comum, balador, que abrange as localidades de Macapá (02), Óbidos (10), Itaituba (18) e Jacareacanga (16).

Com relação ao aspecto social o gráfico a seguir demonstra as preferências lexicais levando em conta o gênero dos informantes: 
Gráfico 05: Frequência dos itens baladeira/estilingue - dimensão diagenérica.

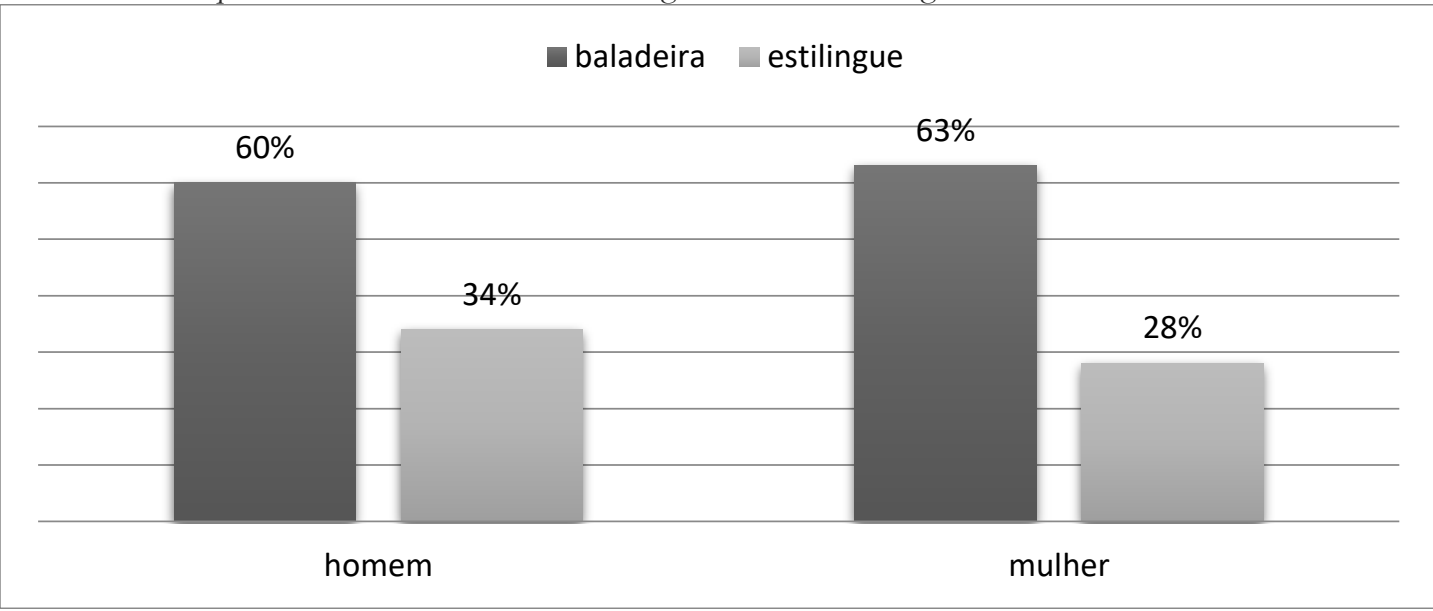

Com base no gráfico, observa-se que baladeira é o item mais utilizado tanto por homens quanto por mulheres nortistas os quais o mencionaram em $60 \%$ e $63 \%$ de suas respostas, respectivamente. $\mathrm{O}$ item estilingue também apresentou um número equilibrado de ocorrência entre os dois sexos, com diferença de apenas $6 \%$ da preferência de uso do item pelos homens, para mais. Os dados indicam que no norte do Brasil não há marca característica de gênero para designar o brinquedo analisado.

Para se abordar os dados na perspectiva diageracional é apresentado o seguinte gráfico:

Gráfico 06: Frequência dos itens baladeira/estilingue - dimensão diageracional

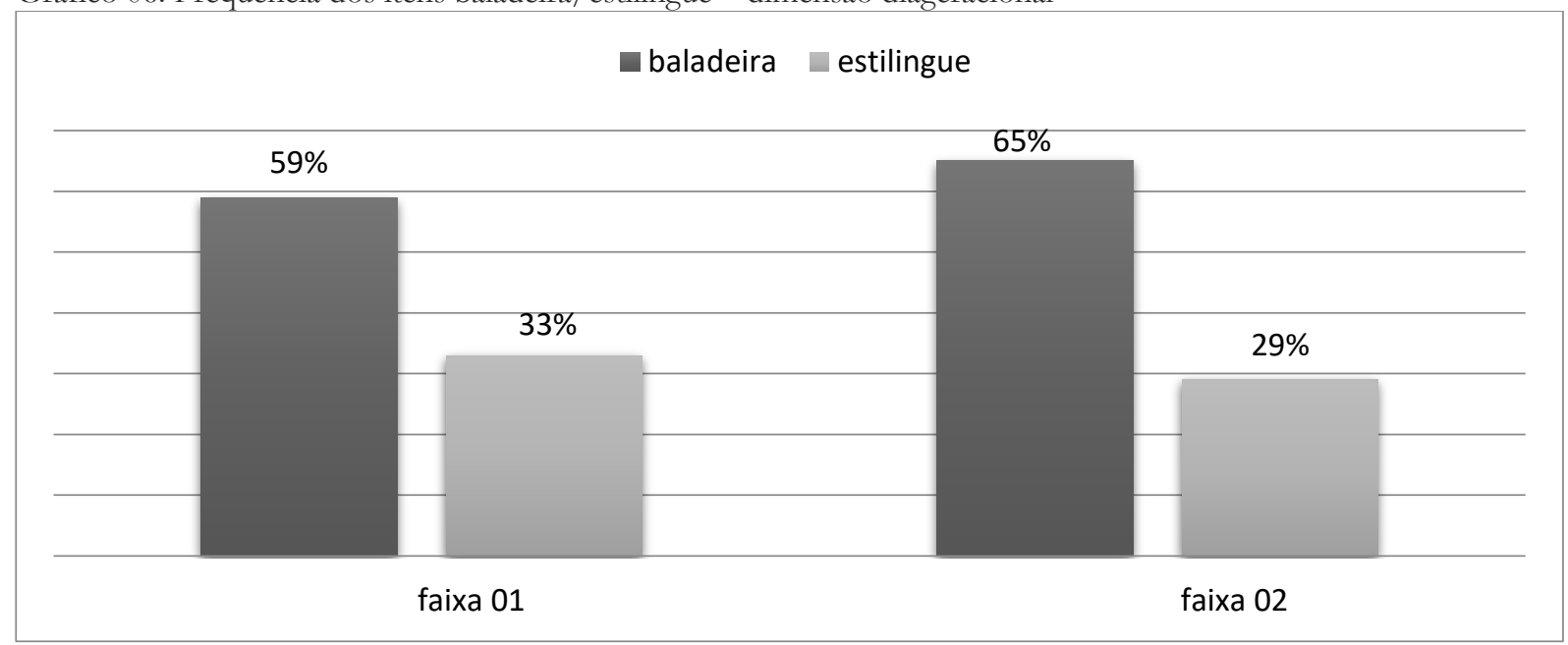

Em relação à idade dos informantes, a preferência por baladeira se manteve na região. Falantes das duas faixas etárias pesquisadas responderam o item em $59 \%$ e $65 \%$ dos dados respectivamente. Os informantes mais velhos o expressaram um pouco mais que os mais jovens e, a respeito de estilingue, o oposto ocorreu, ou seja, os mais jovens o citaram um pouco mais que os falantes mais velhos.

\subsection{CARTA LEXICAL 04: PAPAGAIO DE PAPEL/PIPA}

Para a análise dos itens lexicais papagaio de papel/pipa, apresentamos a seguinte carta: 

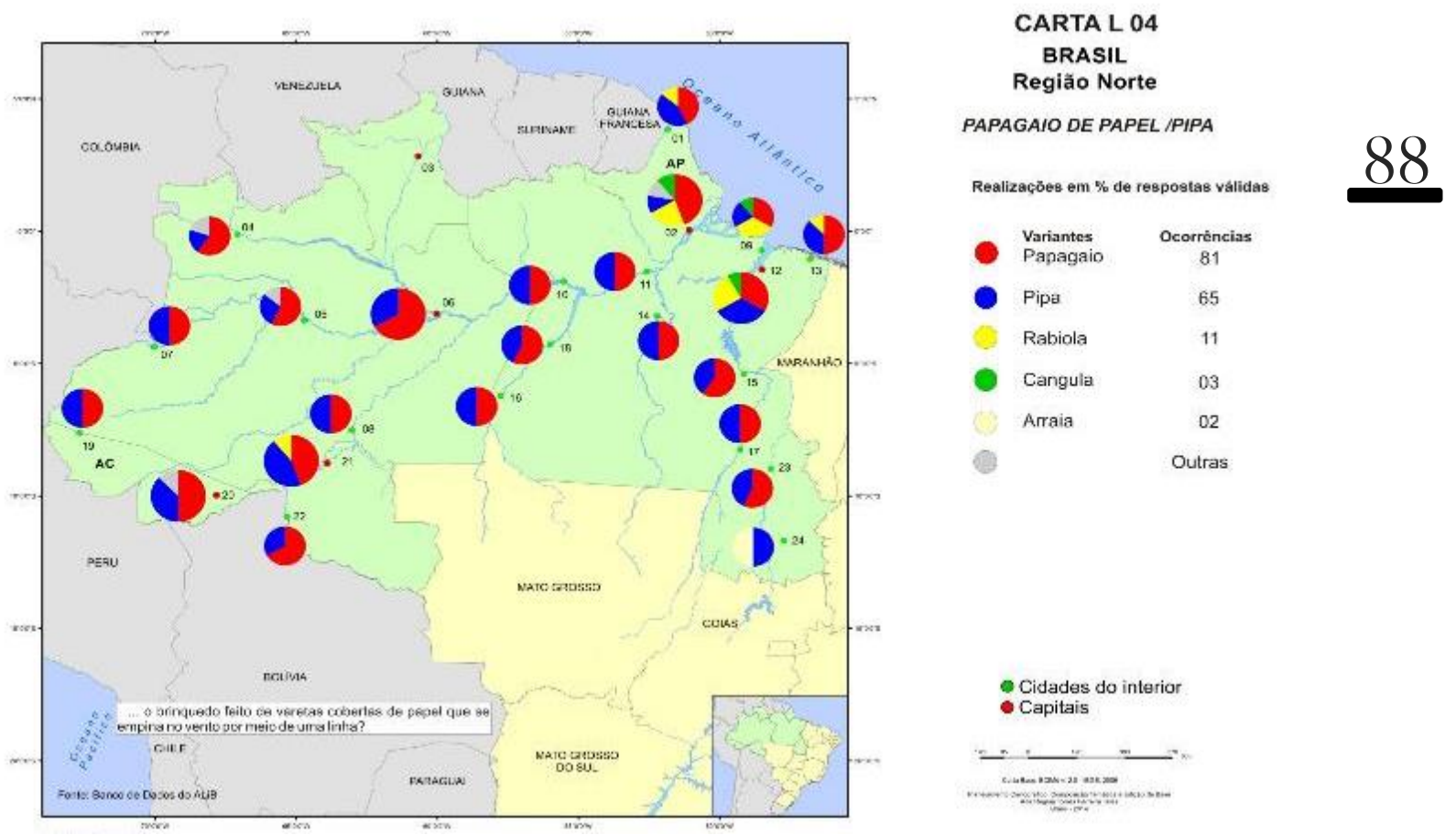

Do ponto de vista local, no Pará os itens registrados em Belém (12) - papagaio, pipa, rabiola e cangula - ocorreram nas cidades interioranas. Papagaio e pipa estiveram presentes em todas as localidades, mas rabiola foi registrado somente nos municípios do nordeste paraense, quais foram Bragança (13) e Soure (09). Esta localidade documentou ainda a variante cangula. No Amazonas, os itens apurados na capital - papagaio e pipa - também foram encontrados no interior, porém, nos municípios de São Gabriel da Cachoeira (04) e Tefé (05) registraram-se formas que não ocorreram em Manaus, como cometa no ponto 04 (São Gabriel da Cachoeira) e gaspetinha no ponto 05 (Tefé). No estado do Acre, Rio Branco (20) e Cruzeiro do Sul (19) registraram basicamente as mesmas formas lexicais - papagaio e pipa - porém, pepeta só ocorreu na capital. Em Rondônia, papagaio e pipa foram os itens mais recorrentes, mas rabiola só foi documentado na capital.

A carta lexical sugere que papagaio e pipa são as formas mais comum na região norte. A primeira forma só não foi registrada na cidade de Natividade (24) no Tocantins e representa 49\% de todos os dados. A segunda forma está presente em todas as localidades consultadas.

Com relação à subáreas com itens lexicais comuns, destaca-se o nordeste da região norte, onde a variante rabiola está documentada em localidades do Pará como em Belém (12), Soure (09), Bragança (13) e Amapá como Macapá (02) e Oiapoque (01). Ainda nessa área geográfica observase a ocorrência de cangula em Belém, Soure e Macapá.

Para análise sob o prisma da dimensão diagenérica, o gráfico a seguir denota as preferências de uso dos itens lexicais papagaio e pipa: 
Gráfico 13: Frequência dos itens papagaio de papel/pipa dimensão diagenérica.

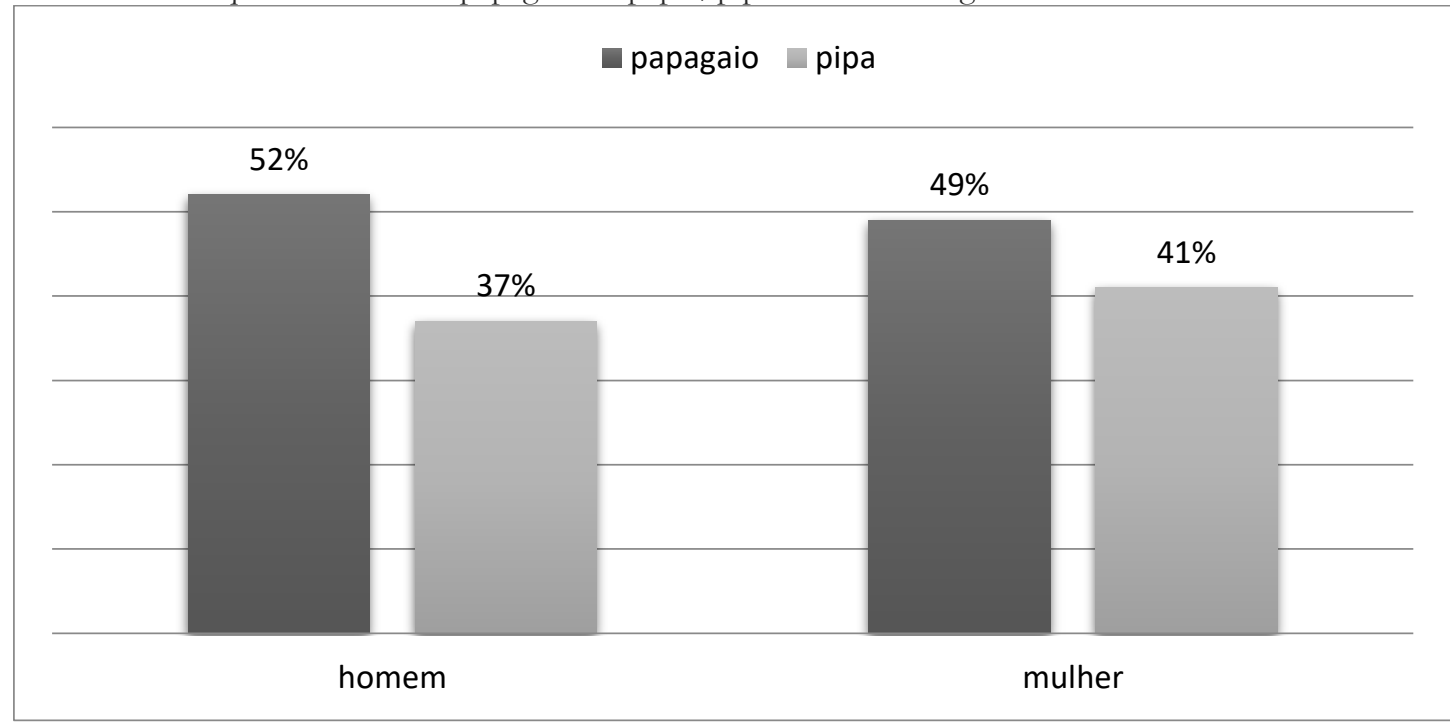

O gráfico mostra que o item papagaio tem preferência significativa tanto por homens quanto por mulheres. Os homens forneceram a forma lexical como resposta em $52 \%$ dos dados e as mulheres em $49 \%$ das respostas, três por cento, somente, a menos que os homens. O item pipa, por outro lado, representou $41 \%$ das respostas entre as mulheres e $37 \%$ entre os homens, o que significa uma pequena diferença, $4 \%$, da preferência feminina por esse item. Os resultados demonstram equilíbrio entre os gêneros em relação ao uso de papagaio e pipa.

Quanto à dimensão diageracional, vejamos o gráfico a seguir:

Gráfico 14: Frequência dos itens papagaio de papel/pipa - dimensão diageracional.

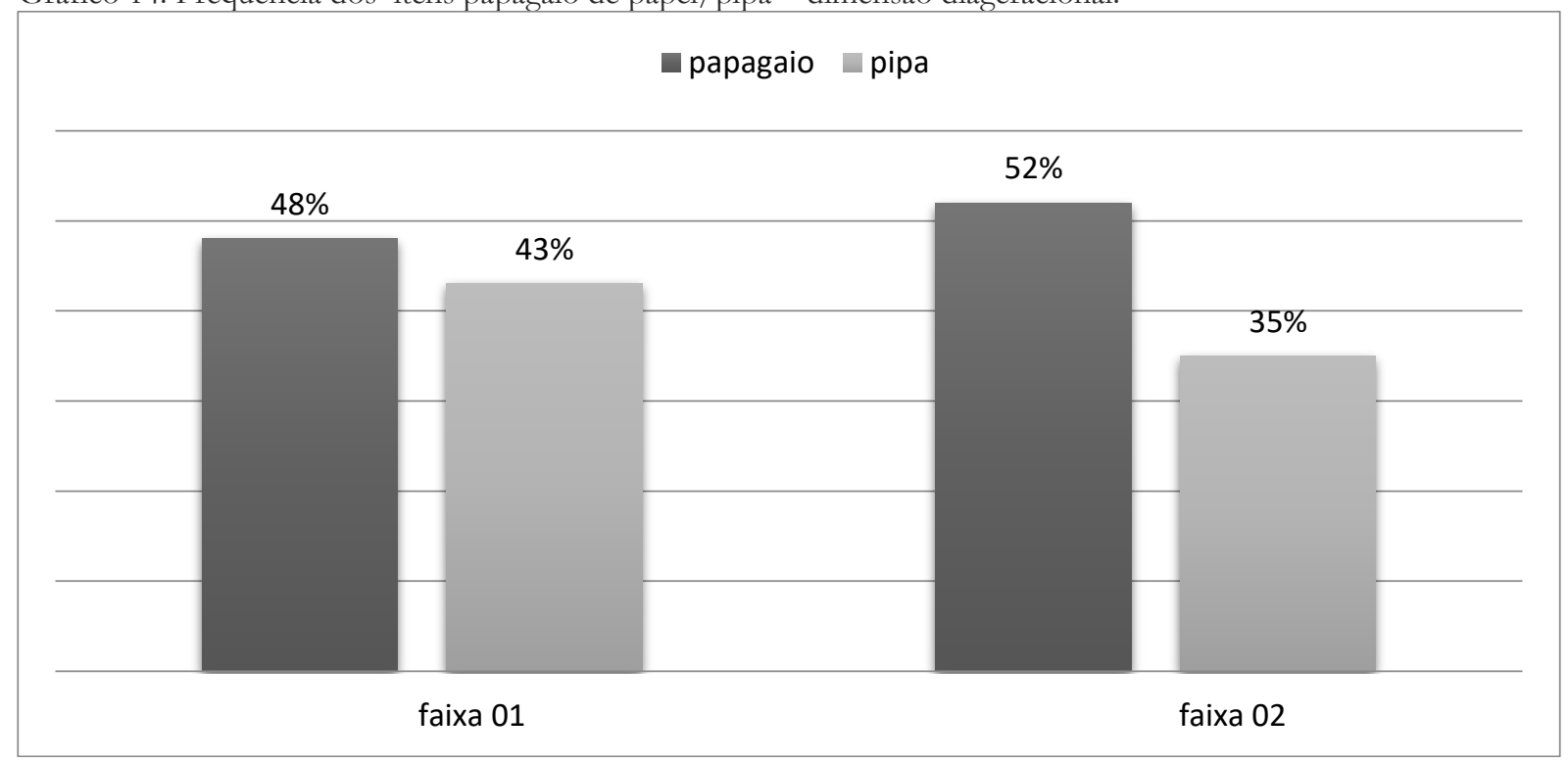

Em relação à idade, falantes mais jovens e mais velhos não demonstraram diferenças significativas quanto ao uso de papagaio/pipa. A primeira faixa etária utilizou papagaio em $48 \%$ de suas respostas e a segunda faixa etária em 52\%. Pipa representa $43 \%$ das respostas da primeira faixa e $35 \%$ da segunda faixa etária. Com base no gráfico, observa-se que pipa é um pouco menos usual na fala dos mais velhos que tendem ao uso de papagaio para nomear o brinquedo. As duas formas, papagaio e pipa, aparecem balanceadas entre os falantes mais jovens. 


\section{CONSIDERAÇÕES FINAIS}

Neste artigo apresentamos alguns aspectos relacionados ao falar da região norte do Brasil no que concerne à variação semântico lexical no campo semântico "Jogos e Diversões Infantis" utilizando os dados do projeto Atlas Linguístico do Brasil (ALiB). Tomamos como aporte teórico para o desenvolvimento da pesquisa os conhecimentos da dialetologia pluridimensional a qual leva em consideração em suas análises aspectos geográficos e sociais.

A respeito da variação semântico-lexical sob a ótica diatópica, os resultados alcançados indicam que os falares da região apresentam itens lexicais peculiares à essa área do Brasil os quais ocorrem concomitantemente com formas que caracterizam o falar nacional. Como exemplo, temos os itens carambela (QSL - 155) que ocorre ao lado de cambalhota, curica (QSL - 159) ao lado de pipa e pira (QSL - 162) ao lado de pega-pega. Ademais, a análise diatópica dos itens lexicais deixou transparecer subáreas na região norte onde formas lexicais em comum ocorrem com frequência. Destacamos a região sudoeste que abrange os pontos de inquérito 15 (Marabá), 17 (Conceição do Araguaia), 23 (Pedro Afonso) onde a lexia tiúba foi registrada nos estados do Pará e do Tocantins. Ainda a região nordeste que inclui os pontos 12 (Belém), 09 (Soure), 02 (Macapá), 01 (Oiapoque) e 13 (Bragança) onde rabiola foi item comum tanto no Pará como no Amapá. Destaca-se, ademais, os pontos 10 (Óbidos), 18 (Itaituba),16 (Jacareacanga), 08 (Humaitá), 21 ( Porto Velho) e 15 (Marabá), onde o item calambiota foi registrado em três estados diferentes, quais foram, Pará, Rondônia e Amazonas, mostrando que o léxico pode ultrapassar as fronteiras estipuladas geograficamente.

A dimensão social revelou particularidades em relação ao uso de algumas formas como carambela que foi preferida pelos falantes mais velhos ao passo que os mais jovens tendenciaram a usar cambalhota. Outrossim, a dimensão diagenérica demonstrou pouca diferença entre as formas utilizadas por homens e mulheres.

As análises feitas mostram que a região norte possui um conjunto lexical bastante significativo do ponto de vista da variação diatópica e apresenta pontos de inquéritos que possuem léxicos em comum e que não ocorrem em outros pontos da região, conforme já frisado. A variedade lexical da região norte ainda precisa de ser mais conhecida e documentada para se contribuir com outros ramos dos conhecimentos como a lexicografia, por exemplo, para que as informações em dicionários sejam mais fiéis ao modo de falar nortista. A título de ilustração, temos o termo peteca que nos dicionários consultados não é registrado como a "bolinha de vidro com que as crianças gostam de brincar" mas somente como a versão de couro com penachos nas pontas. O termo baladeira no dicionário Houaiss é registrado como item comum em Pernambuco e Amazonas, mas os dados da pesquisa atestam o termo por toda a região norte.

Esperamos que a pesquisa tenha apontado trilhas a percorrer e trazido a reflexão pontos que possam dar início a outros estudos com mais fôlego, assim como contribuído para o conhecimento das peculiaridades do falar do norte do Brasil no nível lexical.

\section{REFERÊNCIAS}

CALLOU, D. Quando Dialetologia e Sociolinguística se encontram. Estudos Linguísticos e Literários - Salvador, n 41, p. 33-35, jan/jun, 2010. Programa de Pós-Graduação em língua e cultura, UFBa.

CARDOSO, S. A. Geolingüística: tradição e modernidade. São Paulo: Parábola, 2010.

COMITE NACIONAL DO PROJETO ALiB (Brasil). Atlas Linguístico do Brasil: questionários. Londrina: Ed. UEL, 200.

ELIZAINCÍN,A.Socioygeolinguistica:Nuevaalianzaemlosestudiossobreelusolinguístico.In: EstudosLinguísticoseLiterários, ${ }^{\circ} 41$,Salvador: Programa dePós-GraduaçãoemLínguaeCultura, 2010. p. $14-28$.

RAZKY. A. A dimensão sociodialetal do léxico no projeto Atlas Linguístico do Brasil. SIGNUM: Estudos Linguísticos do Brasil. Londrina. n.16/2, p. 247-270, dez.2013.

THUN, Harald. La geolingüística como lingüística variacional general (com ejemplos delAtlas lin-

https://periodicos.unifap.br/index.php/letras

Macapá, v. 10, n. 1, $1^{\circ}$ sem., 2020 
güístico Diatópico y Diastrático del Uruguay). In: INTERNATIONAL CONGRESSOF ROMANCE LINGUISTICS AND PHILOLOGY (21. : 1995 : Palermo).Atti del XXICongressoInternazionale di Linguistica e Filologia Romanza. Org. Giovanni Ruffino.Tübingen : Niemeyer, 1998. v. 5, p. 701-729. Palermo: Universitá di Palermo.

TRUDGILL,P. Dialect contact, dialectology, and sociolinguistics. Cadernos de Filologia Inglesa, vol. 8, 1999.p. 1-8. 